\title{
Biometria e componentes físico-químicos de romã armazenada sob refrigeração ${ }^{1}$
}

\author{
Inácia dos Santos Moreira ${ }^{2}$, Railene Hérica Carlos Rocha ${ }^{3}$, \\ Emanoela Pereira de Paiva ${ }^{4}$, Helton de Souza Silva ${ }^{5}$, Francisco de Assis de Sousa ${ }^{3}$
}

\begin{abstract}
Biometrics and physicochemical components of pomegranate stored under refrigeration

The commercial cultivation of pomegranate plants has been growing throughout Brazil and has attracted the interest of northeastern fruit producers. However, for the establishment of pomegranate in the in natura fruit market, it is necessary to find out the refrigeration temperature most suitable for commercializing the product in distant markets. This study aimed to characterize the quality of 'Molar' pomegranate, during the storage of in natura fruits under different refrigeration temperatures $\left(6{ }^{\circ} \mathrm{C}, 10{ }^{\circ} \mathrm{C}\right.$ and $\left.12{ }^{\circ} \mathrm{C}\right)$. A completely split-plot randomized design, with four replications and four fruits per plot, was used. It was concluded that 'Molar' pomegranates stored at $12{ }^{\circ} \mathrm{C}$, for 36 days, followed by two days at $24{ }^{\circ} \mathrm{C}$ and $43 \pm 5 \%$ $\mathrm{RH}$, remain satisfactory for in natura commercialization, without affecting their biometric quality attributes and with small losses in their physicochemical properties. The temperatures of $6^{\circ} \mathrm{C}$ and $10{ }^{\circ} \mathrm{C}$ may also be used for the refrigerated storage of the 'Molar' pomegranate, but with a smaller volume of juice per fruit.
\end{abstract}

KEY-WORDS: Punica granatum L.; shelf life; food preservation.

\section{INTRODUÇÃO}

A romãzeira (Punica granatum L.) é considerada excelente para o cultivo em zonas áridas e semiáridas, especialmente devido à resistência a condições de baixa precipitação e umidade relativa do ar (Ercisli 2004). Seus frutos atrativos e ricos em compostos fenólicos têm despertado interesse em várias regiões do mundo, tanto para fins alimentares como farmacêuticos.

\section{RESUMO}

O cultivo comercial de romãzeira vem crescendo em todo o Brasil e tem despertado o interesse de produtores de frutíferas do Nordeste. No entanto, para o estabelecimento da romã no mercado de frutos in natura, é necessário determinar a temperatura de refrigeração mais apropriada à comercialização do produto, em mercados distantes. Este trabalho objetivou caracterizar a qualidade da romã 'Molar', durante o armazenamento dos frutos in natura sob diferentes temperaturas de refrigeração $\left(6{ }^{\circ} \mathrm{C}, 10^{\circ} \mathrm{C}\right.$ e $\left.12{ }^{\circ} \mathrm{C}\right)$. $\mathrm{O}$ experimento foi instalado em delineamento inteiramente casualizado, com parcelas subdivididas, utilizando-se quatro repetições e quatro frutos por parcela. Concluiu-se que romãs 'Molar' armazenadas a $12{ }^{\circ} \mathrm{C}$, por 36 dias, seguidos de dois dias a $24^{\circ} \mathrm{C}$ e $43 \pm 5 \%$ de UR, se mantêm satisfatórias para comercialização in natura, sem prejuízos aos atributos de qualidade biométricos e com pequenos prejuízos aos atributos físico-químicos. As temperaturas de $6{ }^{\circ} \mathrm{C}$ e $10{ }^{\circ} \mathrm{C}$ também podem ser utilizadas para o armazenamento refrigerado da romã 'Molar', resultando, porém, em menor volume de suco por fruto.

PALAVRAS-CHAVE: Punica granatum L.; vida de prateleira; conservação de alimentos.

A romã é um fruto com alto potencial nutracêutico, devido à presença de antocianinas (delfinidina, cianidina e pelargonidina), quercetina, ácidos fenólicos (cafeico, catequínico, clorogênico, orto e paracumárico, elágico, gálico e quínico) e taninos (punicalagina) (Noda et al. 2002).

Seu cultivo está, principalmente, alicerçado nos continentes Europeu e Asiático, sendo a Índia, Irã, China e Turquia os principais produtores da fruta (Ercisli et al. 2007). O Brasil possui condições eda-

1. Trabalho recebido em out./2014 e aceito para publicação em jan./2015 (http://dx.doi.org/10.1590/1983-40632015v4532501).

2. Universidade Federal de Campina Grande (UFCG), Centro de Tecnologia e Recursos Naturais, Campina Grande, PB, Brasil. E-mail: inaciamoreira@ymail.com.

3. Universidade Federal de Campina Grande (UFCG), Centro de Ciência e Tecnologia Agroalimentar, Pombal, PB, Brasil. E-mails: raileneherica@ccta.ufcg.edu.br, franciscoufcg@gmail.com.

4. Universidade Federal Rural do Semiárido (Ufersa), Departamento de Ciências Vegetais, Mossoró, RN, Brasil. E-mail: emanuelappaiva@hotmail.com.

5. Universidade Federal da Paraíba (UFPB), Centro de Ciências Agrárias, Departamento de Solos, Areia, PB, Brasil. E-mail: heltonssilva@gmail.com. 
foclimáticas favoráveis ao crescimento vegetativo, florescimento, frutificação e produção de frutos de romãzeira de boa qualidade (Cardoso et al. 2011).

O Nordeste brasileiro apresenta condições ideais para o cultivo dessa frutífera, a qual tem despertado o interesse de produtores da região. $\mathrm{Na}$ cidade de Sousa (PB), encontra-se instalado um dos maiores pomares brasileiros da cultura da romã, com cerca de 70 hectares. O cultivo iniciou-se com as variedades 'Molar' e 'Wonderful', que foram importadas da Califórnia e propagadas por sementes. Atualmente, o pomar está em fase de produção, e uma das maiores preocupações dos produtores é a melhoria da qualidade do fruto in natura e a implementação de tecnologias para a sua conservação.

A área cultivada vem se expandido, tendo-se em vista a demanda pelo produto, por parte das indústrias de alimentos, farmacêutica e de cosméticos. Há, também, uma tendência de ampliação da comercialização do fruto in natura, prolongando sua vida útil e, consequentemente, favorecendo sua comercialização em mercados mais distantes. Com base nisso, a refrigeração é uma alternativa de armazenamento interessante para manter a qualidade do fruto recém-colhido por um maior período.

A determinação do estádio de maturação adequado para a colheita, associado à temperatura ideal de refrigeração, pode potencializar o período de conservação pós-colheita da romã. Portanto, o manuseio adequado dos frutos, associado a tecnologias que reduzem sua deterioração, possibilita a comercialização do fruto in natura em mercados mais distantes, à medida que reduz a perda dos atributos de qualidade visual, físico-químicos e nutricionais.

O presente trabalho objetivou caracterizar a qualidade da romã 'Molar', durante o armazenamento sob diferentes temperaturas de refrigeração.

\section{MATERIAL E MÉTODOS}

Romãs da variedade 'Molar' foram adquiridas em um pomar comercial, localizado em Várzeas de Sousa, no município de Sousa (PB) (06 $45^{\circ} 33^{\prime}$ 'S e $\left.38^{\circ} 13^{\prime} 41^{\prime \prime} \mathrm{W}\right)$, distante $57,2 \mathrm{~km}$ de Pombal (PB). A colheita foi realizada pela manhã, com o auxílio de tesoura de poda, no estádio de maturação comercial. Após a colheita, em fevereiro de 2013, os frutos foram acondicionados em caixas plásticas $(31 \mathrm{~cm} \mathrm{x}$ $36 \mathrm{~cm} \times 56 \mathrm{~cm}$ ) revestidas internamente com jornal, a fim de minimizar danos físicos, e, em seguida, foram transportados para o Laboratório de Análise de Alimentos da Universidade Federal de Campina Grande, Câmpus Pombal (PB).

No laboratório, os frutos foram selecionados de acordo com a uniformidade de tamanho, cor e ausência de defeitos, descartando-se os frutos manchados, rachados ou doentes. Em seguida, realizou-se lavagem dos frutos selecionados em solução contendo detergente neutro a $1 \%$ e, após enxágue, os frutos foram sanitizados com solução de hipoclorito de sódio a $100 \mathrm{ppm}$ de cloro ativo, por cinco minutos. Após secagem ao ar livre, as romãs foram acondicionadas em bandejas de poliestireno $(21 \mathrm{~cm} \mathrm{x} 14 \mathrm{~cm})$ e embaladas com filme plástico de policloreto de vinila (PVC), com $12 \mu \mathrm{m}$ de espessura, e armazenadas sob condições de refrigeração em BOD.

$\mathrm{O}$ experimento foi instalado em delineamento inteiramente ao acaso, em esquema de parcelas subdivididas no tempo, com quatro repetições e quatro frutos por parcela. As parcelas foram representadas pelas temperaturas de $6 \pm 2{ }^{\circ} \mathrm{C}, 10 \pm 2{ }^{\circ} \mathrm{C}$ e $12 \pm 2{ }^{\circ} \mathrm{C}$, com $57 \pm 5 \%$ de umidade relativa (UR). As subparcelas foram representadas pelos períodos de avaliações ao longo do tempo de armazenamento refrigerado $(0,12,18,24,30$ e 36 dias após a colheita), com um acréscimo de 2 dias de armazenamento sob condições ambientes $\left(24 \pm 2{ }^{\circ} \mathrm{C}\right.$ e $43 \pm 5 \%$ UR), simulando a vida de prateleira, a cada avaliação.

Para a determinação da perda de massa fresca, os frutos foram pesados, com o auxílio de balança eletrônica de precisão. Os resultados foram expressos em porcentagem, considerando-se a diferença entre o peso obtido no dia da colheita e após cada período de avaliação. O peso de arilos por fruto, sementes por fruto e casca por fruto foram determinados por gravimetria, individualmente em cada fruto, após a separação das partes, utilizando-se balança analítica de precisão. Os resultados foram expressos em porcentagem, considerando-se a proporção entre cada variável e o peso do fruto, durante o armazenamento.

O suco foi obtido por meio de maceração do arilo, em saco plástico. $\mathrm{O}$ volume de suco por fruto foi quantificado individualmente, em proveta volumétrica, e os resultados expressos em porcentagem, considerando-se o rendimento de suco por fruto, por meio da proporção entre o volume de suco e o peso individual de cada fruto, durante o armazenamento.

A partir do suco, foram determinados os índices de vitamina $\mathrm{C}$, sólidos solúveis, acidez titulável e $\mathrm{pH}$. Posteriormente, as amostras foram congeladas 
em freezer doméstico, para as demais análises de qualidade.

A vitamina $\mathrm{C}\left(\mathrm{mg} 100 \mathrm{~mL}^{-1}\right.$ de ácido ascórbico) foi determinada por titulação, com 2,6-dicloro-fenol-indofenol (DFI) (AOAC 2005), e os sólidos solúveis (SS \%) diretamente no suco homogeneizado, por meio de leitura em refratômetro digital (AOAC 2005). A acidez titulável (AT, $\%$ de ácido cítrico) foi determinada por titulometria, utilizando-se solução de hidróxido de sódio $(\mathrm{NaOH}) 0,1 \mathrm{~N}$, padronizada com biftalato de potássio, como titulante (IAL 2008), e o $\mathrm{pH}$ diretamente no suco, com pHmetro da marca Tecnopon (Modelo mPA - 210P, versão 7.1), com inserção direta do eletrodo (IAL 2008). A relação SS/AT foi estabelecida por meio da razão entre as duas variáveis.

Os compostos fenólicos totais ( $\mathrm{mg} 100 \mathrm{~mL}^{-1}$ ) foram determinados a partir do método de Folin \& Ciocalteau, descrito por Waterhouse (2006), com modificações, e os extratos preparados a partir da diluição de $0,5 \mathrm{~mL}$ de suco de romã em $10 \mathrm{~mL}$ de água destilada, sendo deixados em repouso por uma hora. Uma alíquota de $75 \mu \mathrm{L}$ do extrato foi transferida para um tubo, onde foram adicionados $2.050 \mu \mathrm{L}$ de água destilada e $125 \mu \mathrm{L}$ do reagente folin ciocalteau. A mistura permaneceu em repouso por 5 minutos e, logo após, foram adicionados $250 \mu \mathrm{L}$ de carbonato de sódio a $20 \%$, seguindo-se agitação e repouso em banho-maria a $40^{\circ} \mathrm{C}$, por 30 minutos. A curva padrão foi preparada com ácido gálico e as leituras efetuadas em espectrofotômetro, a $765 \mathrm{~nm}$.

Os flavonoides e antocianinas ( $\mathrm{mg} 100 \mathrm{~mL}^{-1}$ ) foram quantificados de acordo com metodologia proposta por Francis (1982). Amostras de 1,0 mL de suco das romãs foram transferidas para tubos de ensaio revestidos com papel alumínio, com adição de $10,0 \mathrm{~mL}$ da solução extratora de etanol $95 \% \mathrm{com} \mathrm{HCl}$ $1,5 \mathrm{~N}$, na proporção de 85:15 (v/v), respectivamente, sendo a leitura realizada em espectrofotômetro. Para determinação de antocianinas, a leitura foi realizada em comprimento de onda de $535 \mathrm{~nm}$, calculado com $\mathrm{o}$ auxílio da seguinte fórmula: fator de diluição $\mathrm{x}$ absorbância/ 98,2. Para os flavonoides, realizou-se a leitura a $374 \mathrm{~nm}$, da seguinte maneira: fator de diluição x absorbância/ 76,6.

Os dados foram submetidos à análise de variância e de regressão, sendo os modelos lineares e não lineares escolhidos com base no potencial para explicar o fenômeno biológico em questão, no coeficiente de determinação e na significância dos coe- ficientes de regressão. Para as análises, empregou-se o programa computacional Sisvar (Ferreira 2000).

\section{RESULTADOS E DISCUSSÃO}

Houve aumento na perda de massa fresca (PMF), com o avanço do tempo de armazenamento, não havendo diferença estatística entre os tratamentos de refrigeração. Aos 12 dias de refrigeração, acrescidos de dois dias em temperatura ambiente, verificou-se PMF acima de $10 \%$. A baixa umidade relativa ( $57 \%$ ) contribuiu para a aceleração da perda de água por transpiração, ocasionando murchamento e diminuição nos parâmetros físicos, como largura e comprimento dos frutos. Ao final do armazenamento, a PMF máxima foi inferior a $12 \%$ (Figura 1). A perda de massa fresca é consequência da desidratação dos frutos, devido a mudanças na resistência da superfície à transferência de vapor de água e à ocorrência de pequenas fissuras que conectam o interior do fruto com o meio externo (Serrano et al. 2004).

Na romã, a perda de massa fresca pode proporcionar desvalorização do produto, durante o armazenamento, pois altera o formato dos frutos e desidrata a casca, afetando a qualidade visual exigida pelo consumidor. Além disso, a redução na massa pode proporcionar prejuízos econômicos, quando os frutos são comercializados por peso.

Os resultados observados nesta pesquisa corroboram os verificados por Fawole \& Opara (2013), que constataram aumento da PMF em romãs 'Bhagwa' e 'Ruby', armazenadas sob refrigeração às temperaturas de $5{ }^{\circ} \mathrm{C}, 7{ }^{\circ} \mathrm{C}$ e $10^{\circ} \mathrm{C}$, a $92 \%$ UR, com o aumento do tempo de armazenamento. As

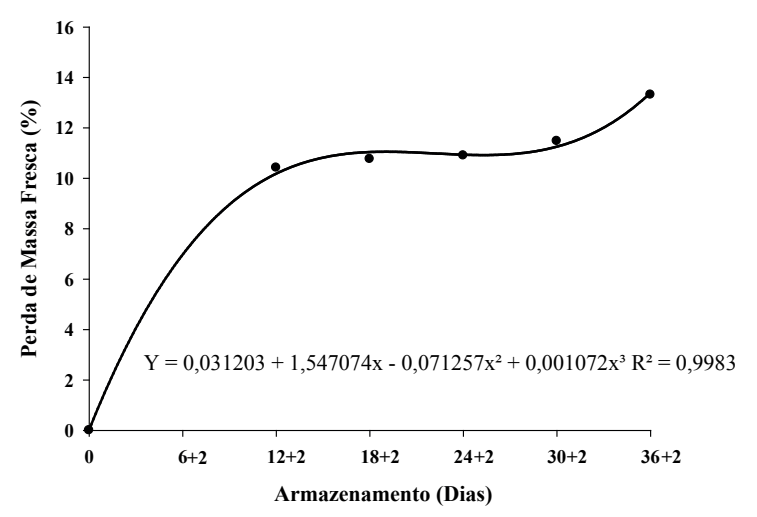

Figura 1. Perda de massa fresca, em romã 'Molar', durante o período de avaliação dos frutos mantidos sob armazenamento refrigerado (Pombal, PB, 2013). 
maiores PMF ocorreram nos frutos armazenados às temperaturas de $7{ }^{\circ} \mathrm{C}$ e $10{ }^{\circ} \mathrm{C}$.

Ao final de 16 semanas de armazenamento, apenas os frutos estocados a $5{ }^{\circ} \mathrm{C}$ foram considerados apropriados para comercialização, com PMF inferior a $20 \%$. No entanto, considerando-se as perdas admissíveis de $20 \%$ de massa dos frutos, todos os tratamentos de armazenamento utilizados na pesquisa proporcionaram condições favoráveis ao armazenamento de frutos de romã 'Molar'.

$\mathrm{O}$ peso de arilos por fruto, assim como o peso de sementes sem arilo por fruto, apresentaram aumentos lineares, conforme o avanço do tempo de armazenamento (Figuras 2a e 2b). Comportamento semelhante foi observado para o volume de suco por fruto, que aumentou de, aproximadamente, $28 \%$, no início do armazenamento, para $30 \%$, ao final do período de armazenamento, para os frutos mantidos às temperaturas de $6^{\circ} \mathrm{Ce} 10^{\circ} \mathrm{C}$. Verificou-se aumento ainda mais acentuado à temperatura de $12{ }^{\circ} \mathrm{C}$, chegando a atingir $32 \%$, aos 36 dias de armazenamento (Figura 2d). De forma inversa, houve redução no peso da casca por fruto, durante o armazenamento, em todas as temperaturas estudadas (Figura 2c).

Esse comportamento ocorreu em virtude de a perda de massa ter sido maior na superfície externa do fruto, sendo evidenciado pela desidratação dos tecidos da casca. Internamente, porém, ao longo do armazenamento, evidenciou-se a integridade dos constituintes do fruto, como sementes e arilos. O valor obtido para o rendimento de arilos, suco, sementes e casca têm papel importante, no caso da romã. Esses atributos podem ser empregados na seleção do melhor tempo e temperatura de armazenamento, levando-se em consideração um maior aproveitamento do fruto, tanto para o consumo in natura quanto para os processos industriais a que se destina.

A temperatura de refrigeração de $12{ }^{\circ} \mathrm{C}$ se destaca como a mais promissora para o armazenamento de frutos de romã 'Molar', proporcionando as melhores características biométricas relacionadas ao rendimento dos frutos.

Os sólidos solúveis apresentaram decréscimo, com ajuste quadrático, ao longo do armazena-

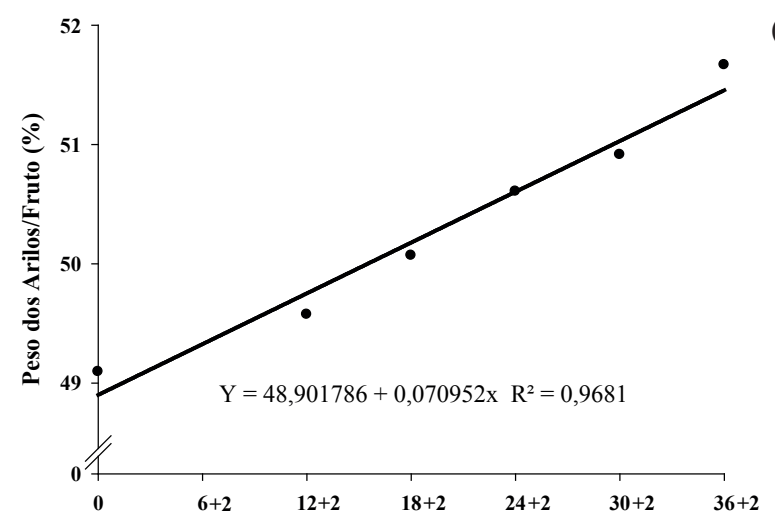

(a)

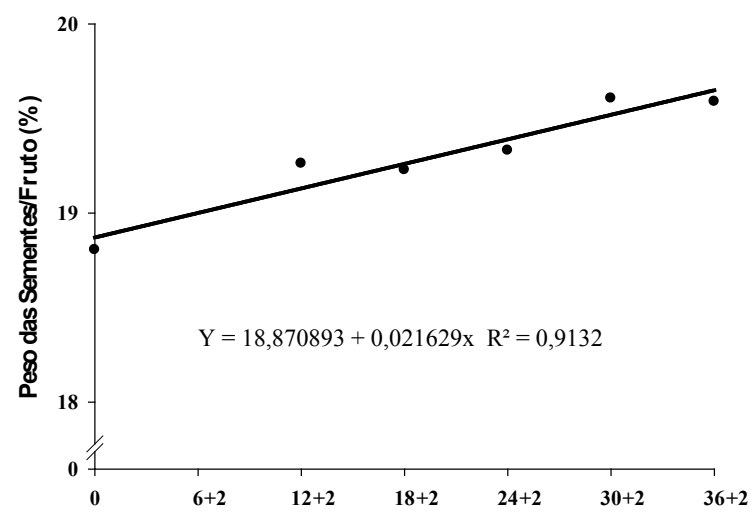

(b)
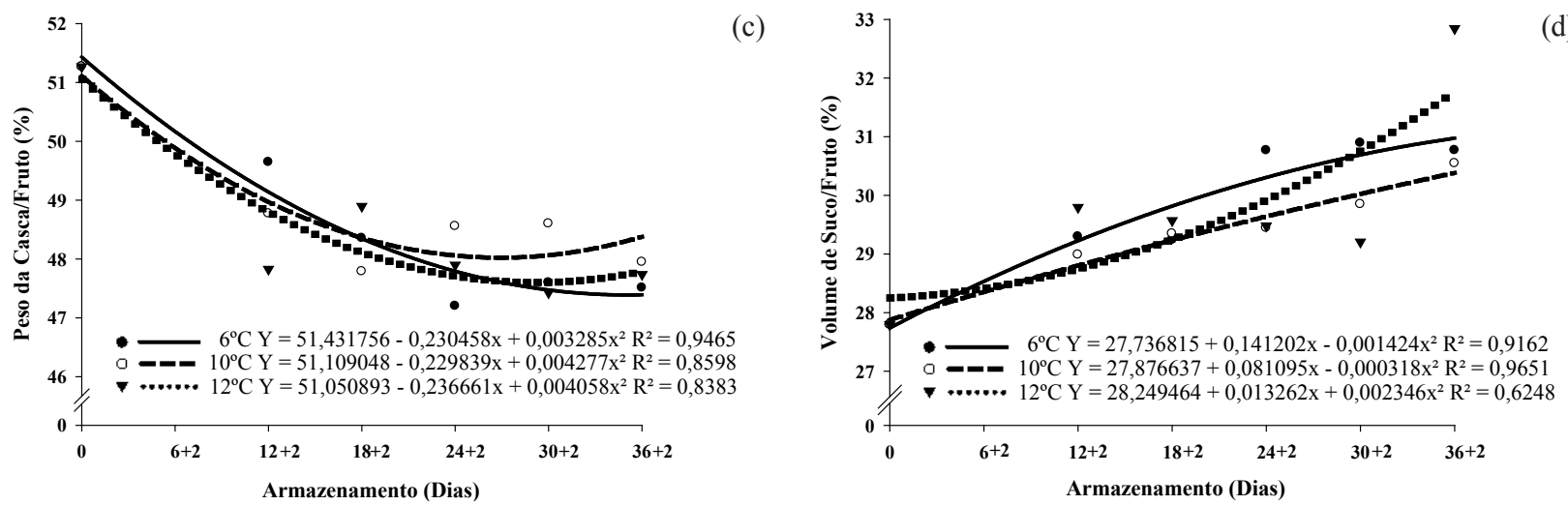

Figura 2. Porcentagem de arilos (a), sementes (b), casca (c) e volume de suco (d), em romã 'Molar', durante o período de avaliação dos frutos mantidos sob armazenamento refrigerado a $6{ }^{\circ} \mathrm{C}, 10^{\circ} \mathrm{C}$ e $12^{\circ} \mathrm{C}$ e shelf life de dois dias $\left(24^{\circ} \mathrm{C}\right)(\mathrm{Pombal}, \mathrm{PB}, 2013)$. 
mento (Figura 3a). Os valores encontrados neste trabalho estão em concordância com os observados por vários autores. Ozgen et al. (2008), em estudo sobre as propriedades químicas e antioxidantes de romãs cultivadas na Turquia, constataram sólidos solúveis de 16,7\%. Fawole et al. (2012) relataram sólidos solúveis, em romãs cultivadas na África do Sul ('Arakata', 'Bhagwa' e 'Ruby'), de 14,07$15,10 \%$. Türkmen \& Ekşi (2011) encontraram valores de $12,2-17,8 \%$, em romãs cultivadas na Turquia.

A acidez titulável teve tendência de aumento até os 24 dias, com posterior redução ao final do armazenamento, em todas as temperaturas (Figura 3b). De acordo com Maciel et al. (2010), quando uma fruta passa do estado maduro para a senescência, ocorrem várias reações de decomposição, quer seja por hidrólise, oxidação ou fermentação, alterando, assim, a concentração dos íons de hidrogênio e, consequentemente, o $\mathrm{pH}$. Menores valores de acidez foram relatados por Silva et al. (2012), em romã 'Molar' (0,46\% de ácido cítrico).

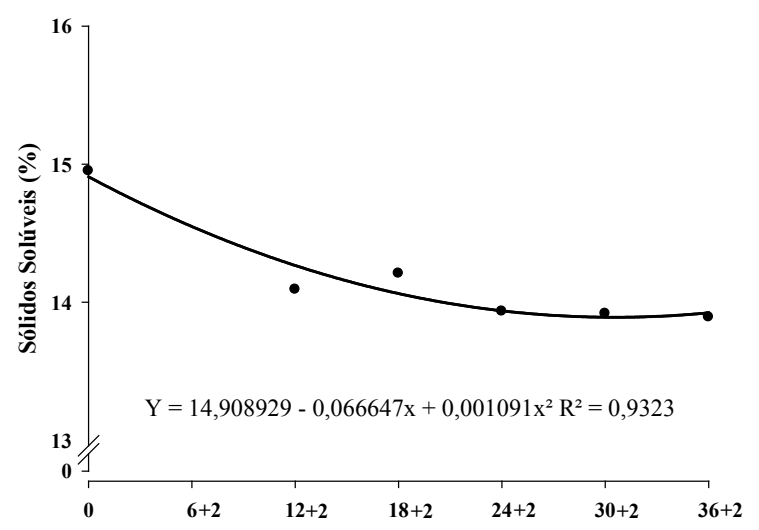

(a)

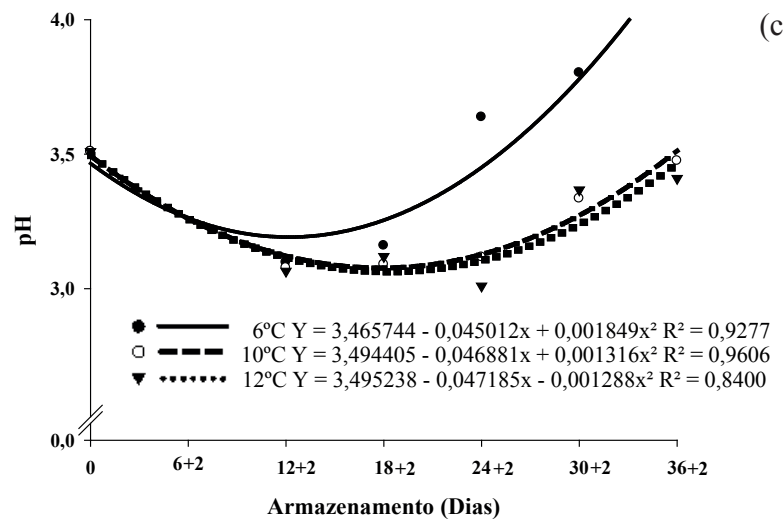

(c)
Quiroz (2009) classifica a romã de acordo com o teor de ácido cítrico do suco. São consideradas 'doces' as variedades com teor de ácido cítrico $<0,9 \%$ e 'ácidas' as com teor $>2 \%$. As variedades com teor de ácido cítrico inferior a $0,9 \%$ são utilizadas, principalmente, para consumo in natura e as variedades com teor acima de 1,0 \% são mais apropriadas para fins industriais.

Verificou-se que a romã 'Molar' armazenada sob as três condições de refrigeração caracteriza-se como 'doce', com valores de 0,6-0,8 \% de ácido cítrico, estando aptas para o consumo in natura. $\mathrm{O}$ $\mathrm{pH}$ variou entre 3 e 4, ao longo do armazenamento (Figura 3c). Esse comportamento foi semelhante ao relatado por Tehranifar et al. (2010), que encontraram pH entre 3,16 e 4,09. Fawole et al. (2012), estudando as propriedades químicas de romã cultivada na África do Sul, observaram valores de $\mathrm{pH}$ entre 3,32 e 3,64.

A razão SS/AT oscilou, em decorrência das mudanças na acidez titulável. Houve declínio nessa relação a partir do décimo quarto dia, nas três temperaturas analisadas, até o trigésimo segundo dia, ao final do armazenamento (Figura 3d). Tal relação

)
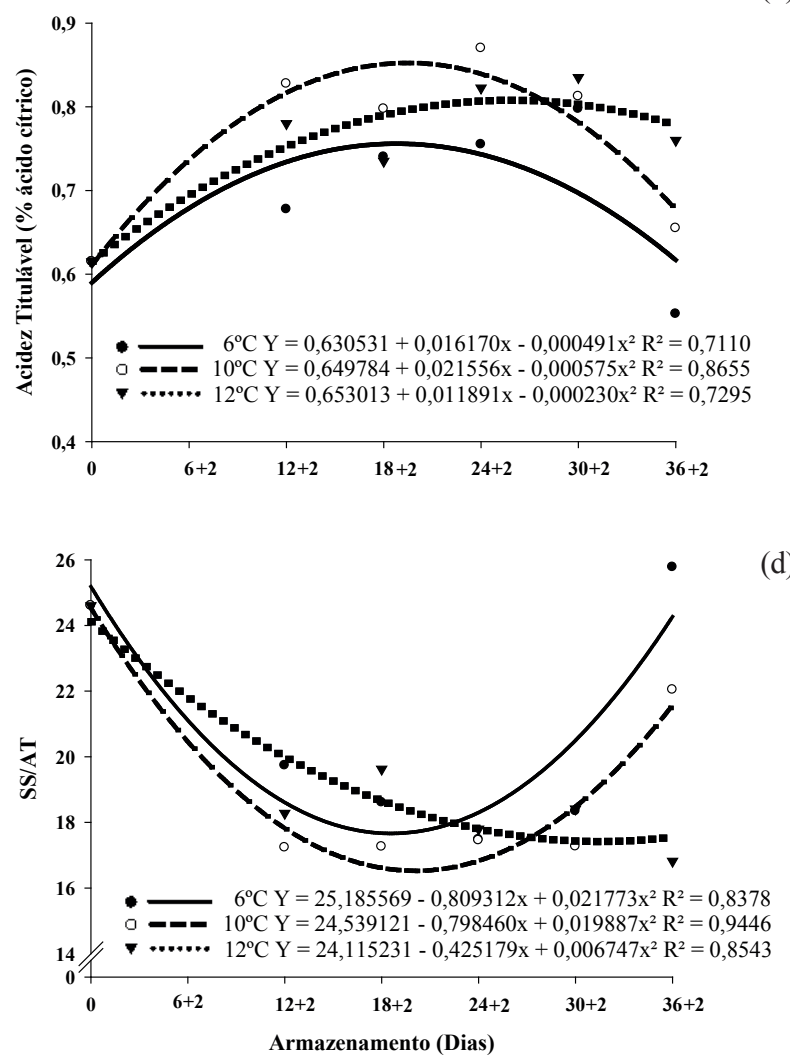

Figura 3. Sólidos solúveis (a), acidez titulável (b), pH (c) e relação sólidos solúveis/acidez titulável (d), em romã 'Molar' armazenada sob refrigeração, seguida de shelf life de dois dias a $24 \pm 2{ }^{\circ} \mathrm{C}$ e $43 \pm 5 \%$ UR (Pombal, PB, 2013). 
aumentou significativamente em frutos armazenados a $6{ }^{\circ} \mathrm{C}$, em comparação aos armazenados a $10{ }^{\circ} \mathrm{C}$ e $12{ }^{\circ} \mathrm{C}$. Valores acima dos encontrados neste trabalho foram relatados por Fawole et al. (2012), em estudo com três cultivares de romãs produzidas na África do Sul. Os autores relataram valores em torno de 45,38-63,13.

$\mathrm{O}$ conteúdo de vitamina $\mathrm{C}$ dos frutos de romã aumentou com o tempo de armazenamento de $10,9 \mathrm{mg} 100 \mathrm{~mL}^{-1}$ para, aproximadamente, $15,0 \mathrm{mg}$ $100 \mathrm{~mL}^{-1}$ de ácido ascórbico (Figura 4a). Em estudo realizado por Tehranifar et al. (2010), foram reportados teores de vitamina $\mathrm{C}$, em romãs cultivadas no Irã, de 9,91-20,92 mg $100 \mathrm{~g}^{-1}$.

A quantidade de compostos fenólicos variou em função da temperatura e do tempo de armazenamento, sendo verificado comportamento cúbico, com o tempo de armazenamento. Primeiro, houve tendência ao declínio, especialmente do décimo quarto ao vigésimo sexto dia de armazenamento. Posteriormente, observou-se aumento a partir do trigésimo segundo dia, sendo esse comportamento semelhante nas três temperaturas (Figura 4b).
Tehranifar et al. (2010) relataram teor de compostos fenólicos maiores que os encontrados neste trabalho: 295,79-985,37 mg $100 \mathrm{~g}^{-1}$.

Provavelmente, esse efeito de declínio e aumento durante o armazenamento tenha sido reflexo de pequenas variações nos estádios de maturação dos frutos, no momento da colheita. Essas alterações são imperceptíveis, considerando-se os critérios de tamanho e cor adotados para a colheita dos frutos e em decorrência da redução no metabolismo e senescência do fruto, corroborando a perda de massa fresca, perda dos diâmetros, redução da acidez e consequente aumento do $\mathrm{pH}$.

Os flavonoides variaram significativamente a $1 \%$ de probabilidade apenas em função do tempo de armazenamento, sendo observado um leve declínio até o décimo quarto dia, seguido por um leve aumento até o vigésimo sexto dia. No trigésimo oitavo dia de armazenamento, houve nova redução dessa variável (Figura 4c). Ardekani et al. (2011), estudando a atividade antioxidante e o conteúdo de flavonoides totais em romãs, encontraram valores de $18,61 \mathrm{mg} 100 \mathrm{~g}^{-1}$ e $36,4 \mathrm{mg} 100 \mathrm{~g}^{-1}$, respectivamente.

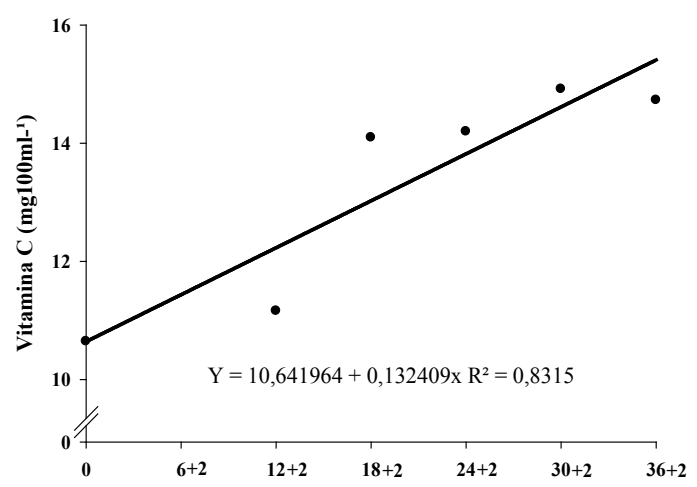

(a)
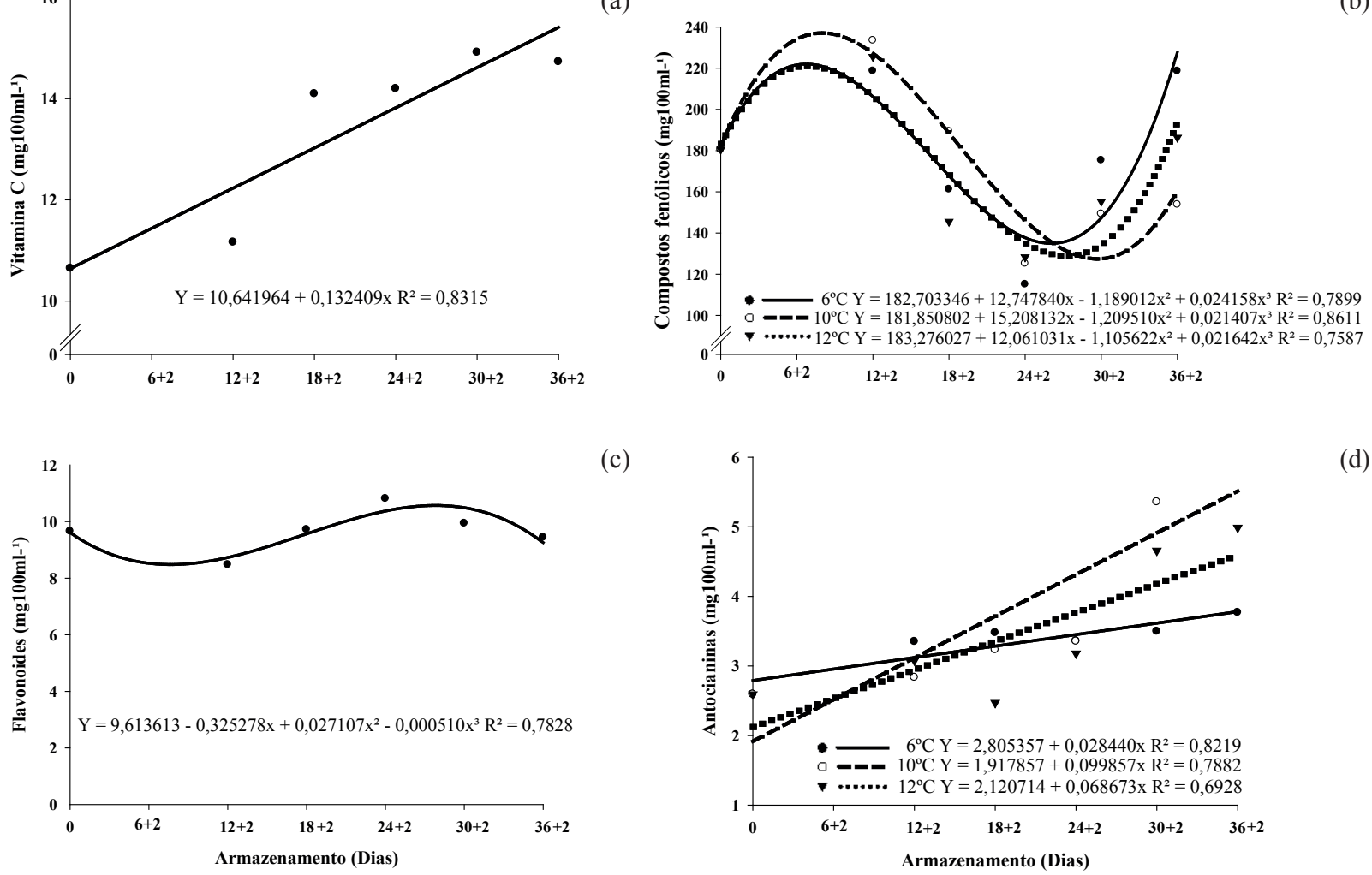

(c)

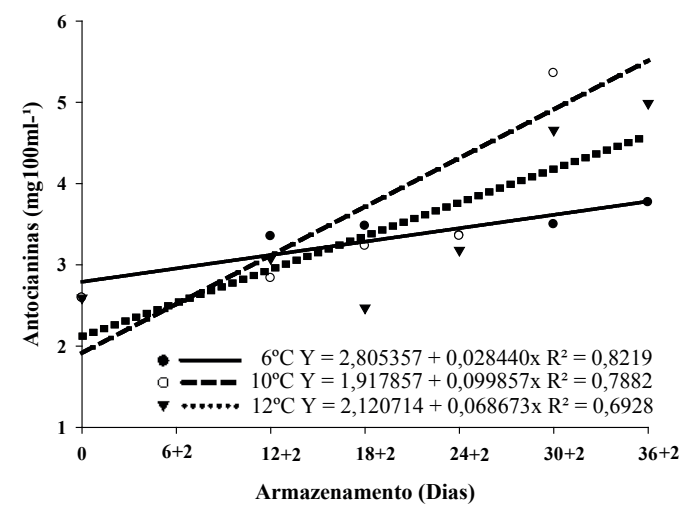

(d)

Figura 4. Vitamina C (a), compostos fenólicos (b), flavonoides (c) e antocianinas (d), em romã 'Molar' armazenada a $6{ }^{\circ} \mathrm{C}, 10^{\circ} \mathrm{C} \mathrm{e}$ $12{ }^{\circ} \mathrm{C}( \pm 2)$ e $85 \%$ UR $\left( \pm 5 \%\right.$ UR), com posterior shelf life de dois dias, a $24 \pm 2{ }^{\circ} \mathrm{C}$ e $43 \pm 5 \%$ UR (Pombal, PB, 2013). 
A quantidade de antocianinas aumentou significativamente com o tempo de armazenamento, às temperaturas de $6{ }^{\circ} \mathrm{C}, 10^{\circ} \mathrm{C}$ e $12^{\circ} \mathrm{C}($ Figura $4 \mathrm{~d})$. Valores semelhantes aos encontrados neste estudo foram relatados por Tehranifar et al. (2010), que observaram 5,56-30,11 mg $100 \mathrm{~g}^{-1}$ de antocianinas, em romãs cultivadas no Irã. Valores superiores foram observados por Fawole et al. (2012), em romãs provenientes da África do Sul.

\section{CONCLUSÕES}

1. Romãs 'Molar' armazenadas a $12{ }^{\circ} \mathrm{C}$, por 36 dias, seguidos de dois dias a $24{ }^{\circ} \mathrm{C}$ e $43 \pm 5 \%$ de UR, se mantêm satisfatórias para comercialização, sem prejuízos aos atributos de qualidade biométricos e com pequenos prejuízos aos atributos de qualidade físico-químicos.

2. As temperaturas de $6{ }^{\circ} \mathrm{C}$ e $10{ }^{\circ} \mathrm{C}$, por 36 dias, seguidos de dois dias a $24^{\circ} \mathrm{C}$ e $43 \pm 5 \%$ de UR, também podem ser utilizadas para o armazenamento refrigerado da romã 'Molar', porém, proporcionam menor volume de suco por fruto.

\section{REFERÊNCIAS}

ARDEKANI, M. R. S. et al. Comparative antioxidant activity and total flavonoid content of Persian pomegranate (Punica granatum L.) cultivars. Iranian Journal of Pharmaceutical Research, Tehran, v. 10, n. 3, p. 519-524, 2011.

ASSOCIATION OF OFFICIAL ANALYTICAL CHEMISTS (AOAC). Official methods of analysis of the Association of Official Analytical Chemists. 18. ed. Gaithersburg: AOAC, 2005.

CARDOSO, J. E. et al. Ocorrência e controle químico da antracnose em plantio comercial da romãzeira no Estado do Ceará. Fortaleza: Embrapa, 2011. (Comunicado técnico, 165).

ERCISLI, S. A short review of the fruit germplasm resources of Turkey. Genetic Resources and Crop Evolution, Dordrecht, v. 51, n. 4, p. 419-435, 2004.

ERCISLI, S. et al. The genotypic effects on the chemical composition and antioxidant activity of sea buckthorn (Hippophae rhamnoides L.) berries grown in Turkey. Scientia Hoticulturae, Amsterdam, v. 115, n. 1, p. 27-33, 2007.

FAWOLE, O. A.; OPARA, U. L. Changes in physical properties, chemical and elemental composition and antioxidant capacity of pomegranate (cv. Ruby) fruit at five maturity stages. Scientia Horticulturae, Amsterdam, v. 150, n. 1, p. 37-46, 2013.
FAWOLE, O. A.; OPARA, U. L.; THERON, K. I. Chemical and phytochemical properties and antioxidant activities of three pomegranate cultivars grown in South Africa. Food and Bioprocess Technology, New York, v. 5, n. 7, p. 2934-2940, 2012.

FERREIRA, D. F. Análises estatísticas por meio do Sisvar para Windows versão 4.0. In: REUNIÃO ANUAL DA REGIÃO BRASILEIRA DA SOCIEDADE INTERNACIONAL DE BIOMETRIA, 45., 2000, São Carlos. Programas e resumos... São Carlos: UFSCar, 2000. p. 255-258.

FRANCIS, F. J. Analysis of anthocyanins in foods. In: MARKAKIS, P. (Ed.). Anthocyanins as food colors. New York: Academic Press, 1982. p. 181-207.

INSTITUTO ADOLFO LUTZ (IAL). Normas analiticas do Instituto Adolfo Lutz: métodos químicos e físicos para análise de alimentos. 4. ed. São Paulo: IAL, 2008.

MACIEL, M. I. S. et al. Caracterização físico-química de frutos de genótipos de aceroleira (Malpighia emarginata D.C.). Ciência e Tecnologia de Alimentos, Campinas, v. 30, n. 4, p. 865-869, 2010.

NODA, Y. et al. Antioxidant activities of pomegranate fruit extract and its anthocyanidins: delphinidin, cyaniding and pelargonidin. Journal of Agricultural Food Chemistry, Washington, DC, v. 50, n. 1, p. 166-171, 2002.

OZGEN, M. et al. Chemical and antioxidant properties of pomegranate cultivars grown in the Mediterranean region of Turkey. Food Chemistry, Oxford, v. 111, n. 3, p. 703-706, 2008.

QUIROZ, I. Granados, características generales. In: GRANADOS, PERSPECTIVAS Y OPORTUNIDADES DE UN NEGOCIO EMERGENTE, 2009, Santiago. Anais... Santiago: Fundación Chile, 2009. p. 6-13.

SERRANO, M. et al. Role of calcium and heat treatments in alleviating physiological changes induced by mechanical damage in plum. Postharvest Biology and Technology, Amsterdam, v. 34, n. 2, p. 155-167, 2004.

SILVA, L. M. M. et al. Parâmetros físico-químicos de duas variedades de romã produzidas no sertão paraibano. In: CONGRESSO BRASILEIRO DE FRUTICULTURA, 22., 2012, Bento Gonçalves. Anais... Bento Gonçalves: Sociedade Brasileira de Fruticultura, 2012. p. 1749-1753.

TEHRANIFAR, A. et al. Investigation of physico-chemical properties and antioxidant activity of twenty Iranian pomegranate (Punica granatum L.) cultivars. Scientia Horticulturae, Amsterdam, v. 126, n. 2, p. 180-185, 2010.

TÜRKMEN, İ.; EKŞI, A. Brix degree and sorbitol/xylitol level of authentic pomegranate (Punica granatum) juice. Food Chemistry, Oxford, v. 127, n. 3, p. 1404-1407, 2011.

WATERHOUSE, A. Folin-ciocalteau micromethod for total phenol in wine. 2006. Disponível em: <http:// waterhouse.ucdavis.edu/faqs/folin-ciocalteau-micromethod-for-total-phenol-in-wine>. Acesso em: out. 2014. 